\title{
Supporting change and scholarship through review of online resources in professional development settings
}

Jason Ravitz<jason@bie.org> of the Buck Institute for Education specializes in design and evaluation of educational technologies and research on constructivist pedagogy. Christopher Hoadley

$<$ tophe@psu.edu > is Assistant Professor in the College of Education, and School of Information Sciences and Technology at Penn State University. Address for correspondence: Jason Ravitz, Research Director, Buck Institute for Education, 18 Commercial Blvd. Novato, CA 94949 United States, Tel: +1 415883 0122 .

\section{Jason Ravitz and Christopher Hoadley}

\author{
Abstract \\ How can we accelerate innovation and ensure effective dissemination of knowledge \\ about online learning resources? This paper advocates strategies that systematically link \\ online professional development with the research, development, and diffusion cycle. \\ The systemic approach we describe can accelerate knowledge advancement and help \\ manage change by improving communication among teachers, developers, and \\ researchers. The examples that are provided are set within two funded projects in the \\ United States that led to development of two distinct but related strategies -- the Site \\ Feedback Form for Educators (a web site review form used in workshops) and a six- \\ week online netcourse on technology supported assessments. Both examples make it \\ easier to give feedback to developers and offer incentives to do so in ways that help \\ teachers to learn about online resources individually and with colleagues. The examples \\ are discussed with analysis of their strengths and weaknesses in supporting different \\ modes of interaction. We highlight implications for instructional development, \\ professional development, change research, and knowledge management in online \\ communities.
}

\section{Introduction}

The problem of ensuring the development and use of online resources for learning is a many-faceted one: It may be viewed from the perspective of accelerating innovation and diffusion of new practices. How can the best ideas for change be generated, shared and evaluated in a more efficient fashion? The problem can be viewed in terms of professional development: how can we help teachers understand, select and use resources? It can also be viewed from a developer's perspective: how can we improve feedback on the quality of digital resources? The problem can also be viewed from a scholarly perspective: how can we ensure the most cumulative understanding of digital resources, their usefulness, and ways they work best? In this paper we examine one way to potentially work towards each of these goals: embedding teacher feedback in the professional development process in a way that is not merely a learning exercise for the teachers but also contributes to the knowledge of others.

What we are suggesting is designing systems for online professional development that --

1. Make it easier for educators to give developers formative feedback 
about the usability of online educational resources. In doing so, developers will "hit the mark" more often, and will (hopefully) come to depend upon educators' feedback in their work.

2. Provide a built-in incentive for educators to offer reviews by building these experiences into professional development courses and workshops, especially graduate courses.

3. Make it easier to create shared and sustainable databases and discussions of online resources that can be accessed and added to by others. The dynamic nature of online resources will be managed as each cohort updates and adds to the resource database.

Below, we examine the systemic needs of education with respect to online resources, and the prospect that teachers might provide valuable data as part of their professional development activities. This is followed by the two examples and a discussion of implications for the future.

\section{Why do we need more systematic review of digital resources?}

The need for systemic change toward more effective use of digital resources is felt by a number of stakeholder communities. Teachers want to locate and use the highest quality resources; policymakers and evaluators want to identify proven and tested programs; developers want their tools refined and disseminated to appropriate audiences. These issues map onto three ongoing and related challenges: 1) professional development, or training for using online resources ; 2) evaluation of resources for purposes of research and development ; and 3) dissemination and reuse of knowledge and practices, related to knowledge management and metadata. We examine each need below.

\section{Professional development needs}

A professional development system is needed that allows educators to be introduced to new technologies and resources. As noted by Wiley (2000) it is relatively easy for teachers to pick up and use "larger reusable digital resources. . entire web pages that combine text, images and other media or applications to deliver complete experiences, such as a complete instructional event" (p. 7). What seems to be lacking is a system for helping educators to continually learn about new educational resources and more effectively keep track of and inform each other about the best practices for technology supported learning.

Teachers and teacher educators require critical evaluation skills in order to assess online resources and make good decisions about technology use (Peck, Augustine, \& Popp, 2003). Walton \& Archer (2004) note that it is necessary to provide "models and opportunities for practicing evaluation of sources and for developing their own critical frameworks" (p. 174-175) and this includes "exploration and scaffolding in order to facilitate critical and evaluative use of the Web" (p. 184). Other researchers have noted that locating, reviewing and selecting educational resources via the Internet is an 
authentic problem solving task (Orrill, 2000; Chitwood, May, Bunnow, \& Langan, 2000). As noted by Barbera (2004) "with the proliferation of online distance learning comes a requirement for rigorous selection and an analysis of quality (and) articulated dimensions to evaluate the quality of virtual environments" (p. 17). In short, assessing information resources is recognized is an important goal for teachers (National Educational Technology Standards, 2004a; 2004b).

\section{Evaluation, research, and development needs}

Evaluation is another critical component in the technology research and development process. It is critical for the field to continually investigate "how technology can help achieve educational objectives, in what situations, with which students and over what period of time" (CEO Forum, 2001, p. 21). As part of formative evaluation efforts, developers are continually seeking ways to interact with their users in a meaningful way (e.g., McAndrew, Clow, Taylor and Aczel, 2004), particularly at a distance. However, data collection on the effectiveness of online resources is often difficult because the developers may have very limited contact with users.

In the area of summative evaluation we are still a long way from knowing how to assess large-scale technology impacts in general (e.g., see Haertel \& Means, 2000), let alone impacts from reusable educational technologies across the Internet. It can be difficult to document the impacts of online resources when they are used. Frechtling, et al. (1995) determined that in order to reach a solution "it is critical to create non-threatening synergy between dissemination, feedback, and evaluation functions of project management." Hoadley and Pea (2002) question why there is so little accumulated knowledge with billions of dollars spent on educational technology and point to the "divide between academic researchers and practitioners and industry" (p. 330). A similar conclusion was reached by the CEO Forum (2001):

Technology companies must be willing to participate in external evaluations of their products and services...Schools and districts should pilot new assessment tools and provide feedback on how to improve them....The federal government, states, institutions of higher learning and foundations should develop mechanisms to share best practices in order to accelerate the national process of learning how to use technology most effectively." (p. 21).

In short, systems for collecting feedback from educational users of online resources are critical for both formative and summative research and evaluation of educational technologies.

\section{Dissemination and reuse needs}

Another way to conceive of the "gap" that exists between stakeholders is to examine it as a knowledge management and diffusion problem. One gap is between technology users and technology developers, making it more difficult for developers to seek and obtain feedback from users. Another gap is between expert and novice educators, creating a knowledge management and diffusion problem. Early adopters and innovators (Rogers, 
1983) need ways to reflect on and share their technology exploits more effectively - to help others avoid having to "wade through the Internet quagmire looking for critical information about project after project" (Orrill, 2000).

Many have attempted to solve this problem with technologies such as metadata tagging and search engines. "One currently prominent solution is that of resource repositories, in which digital resources developed specifically for teaching purposes, by those who teach, are housed, catalogued and described, in ways that make them accessible across institutions" (Malcolm, 2005, p. 34). Examples include projects like MERLOT, the US National Science Digital Library, the Gateway to Educational Materials (GEM) and others. These virtual online libraries provide searchable collections of instructional resources, often judged by expert reviewers to be worthy of inclusion, or based on the descriptions of the developer (Recker \& Wiley, 2001) However, these diffusion mechanisms have typically lacked a cycle of feedback that is essential for advancing knowledge from use of these online resources and innovations. Ely \& Huberman (1994) highlight the fact that structures and processes for dissemination must include an evaluative component - in order to support not just spreading innovations, but also helping educators to choose from alternative resources, to exchange information about resources and their implementation. Technology may solve the problem of cataloguing, but it will never solve the problems of curation and building quality collections.

It is crucial to find ways to incorporate teacher-generated metadata from diverse contexts into online libraries. In our view, the existence of an authoritative template could make it easier for teachers to provide non-authoritative reviews by allowing their focus to be on the task of reviewing, without being required to learn cataloguing schemes first.

In "portals" like MERLOT and the Eisenhower National Clearinghouse, contributions from the user perspective are often lacking (Recker \& Wiley, 2001). Many online resource libraries have a "rate it" or "offer feedback" link, but these generally appear to be unpopulated. Without teachers reviewing the materials and discussing them, resource libraries risk becoming empty spaces, devoid of life (Curtis, in Ravitz, 1995). Feedback is needed to close the loop among various stakeholders of online educational resources (Shepard, 2000) and catalyzing mechanisms are required to generate knowledge from use of online resources (Malcom, 2005).

Major challenges to effective cataloguing and reuse of learning objects include the "knowledge elicitation bottleneck" and difficulty in "codifying social context" noted by Recker and Wiley (2001). It is often difficult to generate metadata from teachers' perspectives. "People are loath to explicitly contribute reviews without some kind of incentive; hence it is difficult to seed and grow a metadata database" (Recker, Walker, and Wiley, 2000, p. 18).

We argue that these obstacles can be overcome through online professional development efforts that populate databases and includes information about and opportunities for interaction with participants. 


\section{How can we support more systematic review of digital resources? The case for reviewing as teacher professional development}

As stated in the introduction, our approach is to "connect the dots" by linking teachers" needs for authentic professional development on locating, selecting, and reviewing online resources with evaluation and dissemination. Our approach relies on cohorts of teachers going through professional development workshops and classes each year that address educational technologies.

Online courses that deal with educational technology (or face-to-face courses with online components) have the potential to generate a wellspring of knowledge about teaching and learning, not just among individual learners, but across the field. Generating feedback from educators as part of their professional development experience is feasible and need not be a distraction from the goals of teacher professional development. When these goals are wedded, it can help fulfill the promise of the Internet as a collaborative learning environment (Moallem, 2003) and help overcome the isolation of educational stakeholders.

Teacher educators (including workshop leaders) can effectively promote trials of new tools and resources through online activities. They can provide test cases and data about teacher perceptions of various resources (lesson plans, rubrics, tools) including assessments of their value, and how to better facilitate use and reuse in diverse settings. When they test resources in their classrooms, they can provide data that can be used by themselves and others. This approach draws on the traditions of participatory evaluation, or action research (Riding, Fowell, \& Levy, 1995) for purposes of resource evaluation. Data generated by educators may be the most relevant possible information for other educators (Weinberger, 2004) as well as for other interested stakeholders. And, importantly, if it is incorporated into the professional development system, teachers have strong incentives to produce and share this data.

This approach allows ongoing interactions with educators to support innovation and resource improvement, in addition to professional development and dissemination needs. The proposed systematic approach extends the potential benefits of online resources or learning objects by connecting the information requirements of educators with developers, evaluators and managers of online information.

Our notion of feedback goes beyond simple ratings of websites to include more detailed, user-centered and contextually based reviews. What we are recommending is not just to create databases of highly rated materials based on expert use of evaluation rubrics (e.g., MERLOT, 2005, has made detailed criteria for review of online resources available) but a design that encourages meaningful discussions to occur within and across these infrastructures among educators, intermediaries or liaisons, and developers. Glenn \& Whitaker (2004) call for a "structure for creating, evaluating, and sharing open resource materials for educators." Feedback on learning objects has a breadth of audiences and can be obtained from cohorts of educators on an ongoing basis when included as part of teacher professional development. Potentially, this kind of feedback could function in 
the way that open source software development has evolved in the programming community (Harris \& Swan, 2004), in that it would be voluntary and self-sustaining.

The shift that has to occur is this - instead of only being accountable to the learning of individual educators who might use these resources - teachers and teacher educators should be enabled and encouraged to contribute to the larger enterprise of educational technology research. Examination and "tagging" of online resources can create conditions for individual learning and personal knowledge management as well as for diffusion and support of organizational and group learning. Recker \& Wiley note that users of learning objects can generate "non-authoritative" metadata which "is critical in supporting effective discovery and reuse" (p. 3). They devised a reflection and ranking tool that "captures context of use and subjective user ratings" (p. 13). In this case, the teachers are not merely unpaid librarians (or unpaid google-bots) cataloguing resources - they are building a rich knowledge base (both for themselves and others) about the implications of the electronic resources. The construction of such a knowledge base is not only a valuable professional development activity, but also a valuable scholarly one.

\section{Two Examples of Systematic Review as Professional Development}

The potential of the general approach described above is demonstrated by the two examples that follow. In each case, teachers learn about different online tools as a part of their professional development, offer feedback to developers, and have the opportunity to discuss their understandings.

The work being presented was conducted with support from two large collaborative projects funded by the National Science Foundation: the National School Network (1994-1997) and Center for Innovative Learning Technologies (CILT, 1997-2004). In the National School Network (NSN) project, systematic review took place via a Site Feedback Form. In the Center for Innovative Learning Technologies (CILT) project, systematic review took place in an online netcourse. The purpose of the projects was similar. The purpose of NSN was "to unite researchers, administrators, teachers, and students in building local infrastructures to improve educational processes" (Hunter, 1995). This included promoting knowledge sharing both within and across school communities (Hunter, 2002), and with diverse stakeholders. Similarly, the vision for CILT as described by Hoadley \& Pea (2002) was "to form a learning community of researchers, developers, and practitioners from academia, government, industry, and education" (p. 331).

\section{Example 1: Web Site Evaluation Form for Educators}

The first example of teacher feedback on digital resources comes from the National School Network (NSN) project in the US. Many educators expressed the need for evaluative information concerning Internet sites and resources that might be used for educational purposes (e.g., Becker, 1995). In response, we developed an experiment to create a distributed large-scale peer reviewing system. In this system, members would 
contribute reviews of web sites, and benefit by having reviews of their sites made available.

A group of NSN participants developed a series of criteria that teachers, students and community partners would use to evaluate and categorize Web sites and Web-based curriculum. The criteria focused on different types of educational usefulness that were considered exemplary. The form (Figure 1) was designed to provided background information about the reviewers, and then teachers would go back and forth between the web site being reviewed and the review form using multiple views or windows.

Participants completed the form during professional development sessions or university classes in which they examined the qualities of different sites and discussed criteria for judging quality. Each checklist was accompanied by open-ended text boxes for explaining or for offering new criteria. Reviews were posted to an online searchable database. Owners of sites could request user feedback without having to build their own data collection tools, and reviewers of sites could request feedback of their own sites. A 
Figure 1. Example of NSN Site Evaluation/Feedback Form

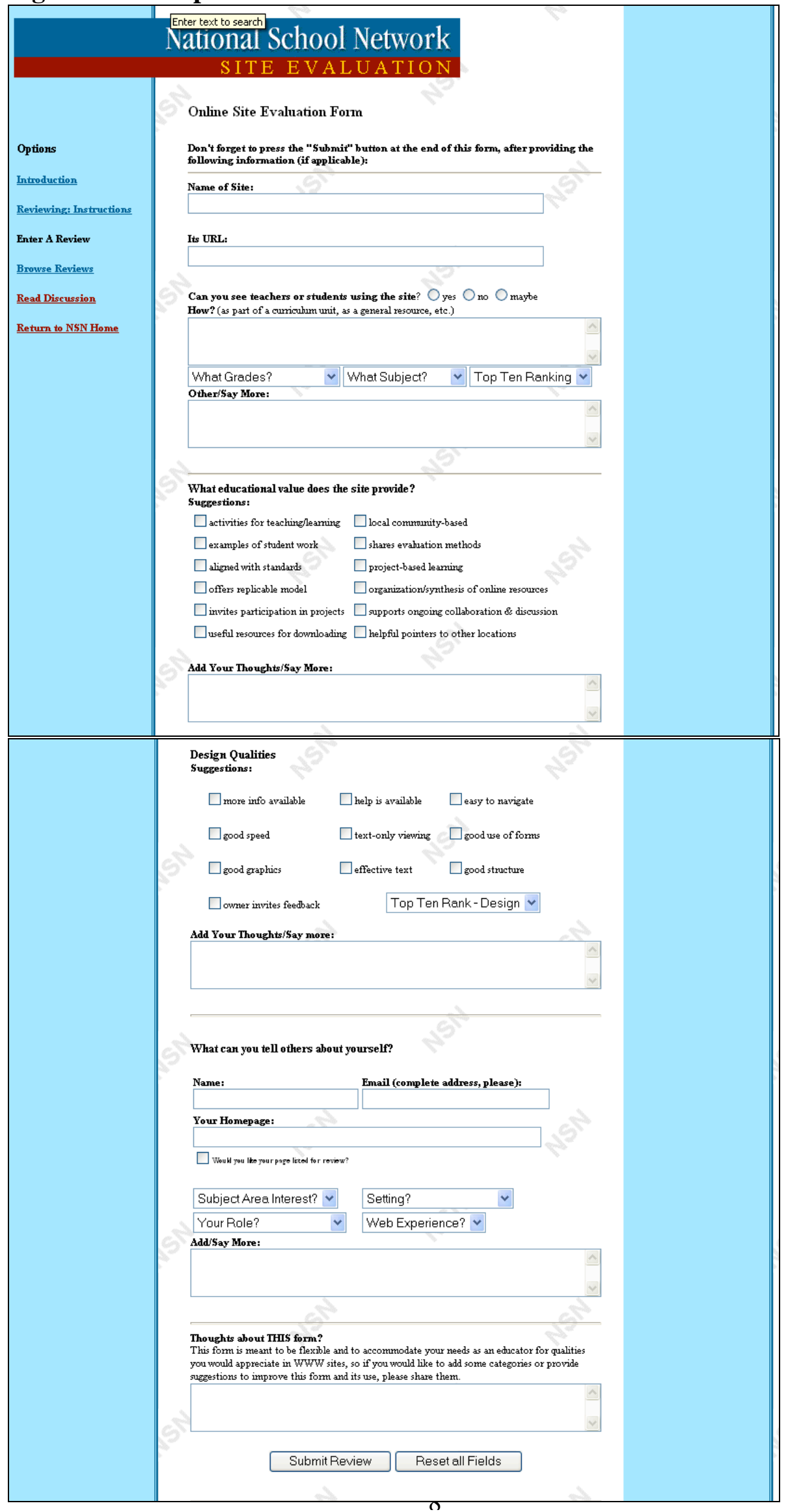


discussion feature allowed participants to discuss the usefulness of sites with instructors and developers and to respond to each other.

The tool was used nationally by the Online Internet Institute (Ravitz \& Serim, 1997), in courses at Syracuse University, at nearby LeMoyne College, and within a consortium of schools in Central New York (Ravitz \& Lake, 1996). Use of the form was spontaneously adopted by teacher educators at Vermont College and Northern Illinois University (without our knowledge until reviews started coming in). This coupled with unsolicited reviews from individuals illustrated the inherent appeal of the project.

A next step was for large web providers to request reviews in order to both increase awareness of their sites, and to receive helpful feedback. Collings and Pearce (2002) noted the usefulness of receiving reviews from remote users by offering valuable and different perspective (p. 274). They concluded that "a site could be evaluated by multiple users or user groups, to the advantage of all concerned" (p. 276). Providing multiple reviews of a single site was field-tested by pre-service teachers at LeMoyne College, in Syracuse, New York, who reviewed the technology page for Madison Metropolitan School District in Wisconsin. Although scheduling problems arose, the plan was to allow someone from Madison to be online interacting with reviewers in realtime. Instead, responses to the reviews came a few days later.

In summary, the form was useful in several ways: for developing a collection of peerreviewed web resources, as an instructional activity for pre-service or in-service educators, as a means of obtaining feedback on the quality of educational web sites, and as a tool for researcher and developers. Teachers who used the form found it to be effective as a professional activity, providing the following comments in their feedback about the form itself:

- $\quad$ "The form was very easy to use and really made the user think about the page he/she was reviewing."

- "There are enough choices to pick from that allow for the web page owners to find out whether or not their page is effective."

- $\quad$ "I am looking forward to the day when I will be able to use this tool regularly to see what other professionals in my field are using"

- $\quad$ "This form provided plenty of opportunity to provide feedback in my own words and also assured that the pertinent questions were addressed."

- "A valuable resource for educators."

There were over 300 reviews in the database collected over a period of two years (see accompanying URL). Table 1 outlines benefits of giving and receiving feedback.

Table 1: Benefits of giving and receiving feedback

\begin{tabular}{|l|l|}
\hline \multicolumn{1}{|c|}{ Teachers Giving Feedback } & \multicolumn{1}{c|}{ Developers Receiving Feedback } \\
\hline - learn to analyze web site or reousrces & - information about potential adopters and how \\
- create your own list of annotated favorites & they perceive your site, \\
- compare with reviews from others & - increased awareness of your site for people who \\
\hline
\end{tabular}


\begin{tabular}{l|l}
\hline - learn from interactions with others & read the reviews \\
- easy way to share links with colleagues
\end{tabular}

The approaches we describe can help educators experience the collaborative potential of the Internet and open new opportunities for generative learning. A constructivist view of learning supports the idea of providing reviews as an added benefit for the learner. Offering such a scaffold or potentially more detailed rubric can help educators apply a set of criteria in a way that requires reflection.

To evaluate and discuss is noted as a strategy for generative learning (Allert, et al., 2004). This approach to inquiry is also consistent with a cognitive view of learning as described in the "frames" discussion of cognitive psychologists (West, Farmer \& Wolff, 1991). Completing the form requires educators to apply a conceptual framework for evaluating online resources. On a daily basis, teachers may be too busy to take these steps, and they may want to see reviews more than contribute them. However, in a professional development setting teachers can be motivated to systematically complete such forms and share feedback with the community. Applying a set of criteria may slow down a teacher initially as she reviews web resources, but there are likely benefits in the added thinking that is required, including potentially improved ability to identify and compare key features in the future.

The resulting database is useful to individual teachers. McAndrew, et al (2004) note that "Despite it being much less glamorous than other e-learning tools, a shared database combining an uncomplicated, familiar interface with a powerful search engine and rich content is arguably one of the most useful knowledge management tools one can provide for motivated independent learners" (p. 743).

Quality concerns can also potentially be addressed through aggregation of peer-reviews as well as through the intervention of the instructor, peers, subsequent cohorts, the developers, or by establishing a reputation system with conduits to reviews from trusted sources. It is also important to understand the reviewers' individual perspectives that influence the reviews (Gauss \& Urbas, 2003), perhaps contextualizing reviews within "social networking" environments that allow networks of people to form who share similar perspectives or values.

Maintenance of the database might be accomplished more easily using software tools. Bannan-Ritland, et al., (2000) describe "an archival engine to clear the database of unwanted and outdated contributions" (p. 40). Another solution could having teachers verify or update entries in addition to (or in preparation for) contributing their own. Sloppy, inaccurate, or out-of-date reviews, or entries consisting of "spam", might easily be refuted or flagged by others. To illustrate this, one negative review in the NSN database was rebutted as follows: "This review is not consistent with the enthusiasm of teachers shown in the guestbook...It would be appropriate for the reviewer to review the material more carefully." Potentially, this suggests an approach to decentralized authority that could borrow from the scholarship model, as outlined by Hutchings \& 
Ravitz \& Hoadley, To appear in British Journal of Educational Technology March, 2005

Shulman (1999) with reviews being "open to critique and evaluation, and in a form that others can build on".

\section{Example 2: Netcourse on Technology Supported Assessments}

The second example of teacher feedback on digital resources comes from the Center for Innovative Learning Technologies, or CILT (http://www.cilt.org). Like NSN, CILT also promoted trials of innovations and sharing of results (Pea, et al., 1999; Sabelli \& Pea, 2004) with one focus being on technology supported assessments for learning. This example is included because it highlights the relationships that can be built between developers and educators as part of their professional development. The discussion of this example is brief because it has been described elsewhere (Ravitz, 2004).

A major CILT initiative involved designing, offering, and moderating a series of netcourses - online short courses for researchers and educators. The Technology Supported Assessments (TSA) netcourse was conducted entirely online using Blackboard. It lasted 6 weeks and ran twice (in the spring and summer of 2001) as part of a U.S. Department of Education PT3 Catalyst Grant involving the Concord Consortium in Concord, MA and the University of Virginia. Students in the course represented a range of individuals from teachers to school administrative professionals to higher education professors and instructional technologists; many had responsibility for advancing technology use at their institutions, offering the potential for catalyzing reuse in local settings. Enrollment in the netcourse was 20 for the first run, and 14 for the second run.

The course focused on the central role of formative assessment in supporting learners (e.g., Black \& Wiliam, 1998) and available research-based tools on the Internet. Goals for the netcourse included bringing technology leaders up to speed on the latest technologies for assessment; fostering reuse of the assessments (and potentially reuse of the netcourse itself) in local settings; and informing tool developers and researchers about the results of the activity. Ravitz (2004) provides samples of discussions that illustrate the benefits to both participants and the developers of this process. More examples are provided online (see accompanying URL).

The design of the course provided participants with readings about the assessment tools and a unique introduction to using the tools. Each week the class read about, tried out, and discussed the applicability of these resources to their work. The course was designed to cognitively support educators using methods of Collison, Elbaum, Haavind \& Tinker (2000) including a "structured asynchronous" format that gives students a week to complete the assignments. The syllabus with a list of readings and activities is available online at http://www.bie.org/Ravitz/syllabus.html.

Development of the netcourse required a partnership between the course author and the tool providers to create customized pathways to introduce participants to the tools. Several tool providers did not yet have complete user-documentation and training systems in place for online users. They were keen to see how someone else could teach others to use their tool via the Internet, or how someone might manage with scant 
documentation. Additional collaboration with developers was required to: 1) obtain or create instructions for using the tool; 2) provide perspective on available readings and research; 3) secure passwords and login access to the tools when necessary; 4) secure technical support during the week scheduled for use; and 5) explain opportunities and costs for reuse to interested educators.

Generally, there was someone from each research and development group who was available to help in these areas. Sometimes there was a high level researcher, a technical support person, and a professional development person. They wanted to explore how more educators becoming users of their assessment tools. To a considerable extent, tool providers (developers) saw a unique opportunity to interact with educators. They were pleased to participate in discussions, as "guest experts" in Blackboard, during their assigned week. They monitored and responded to the progress of class participants, offering insights about their work, and seeking suggestions on the best way to share it with educators. Only one tool in the netcourse was used without the developer participating in the class discussions. The instructor corresponded by email with the developer and shared the results in the class discussion area.

The results of the netcourse demonstrate that developers are interested in feedback and that with little effort they can obtain "fresh eyes" on a recurring basis. Developers who offer their tools in the ways we describe can potentially obtain feedback from cohorts of educators on an ongoing basis and endorsements that will be seen by others. This would also support the process of taking pilot data, validating it, and using it for research. This approach can support an iterative development cycle for which "a crucial part of the prototyping process is the utilization of the design with potential learners" (Tripp \& Bichelmeyer, 1990, p. 37).

While evidence is limited, the netcourse appeared to foster reuse. At a distant college one of the weeks in Blackboard was introduced to an audience of twenty faculty members for their exploration (Ravitz, 2004). In this way, collaboration with teacher educators can help disseminate online resources and supplement data collection.

\section{Comparing the Two Strategies}

Both of the above strategies the Site Feedback Form (Form) and Technology Supported Assessment netcourse (Netcourse) offer generative learning strategies (Allert, et. al., 2004; Collison, et al., 2000) for better understanding online resources, and strategies for promoting interactions that can help developers improve educational offerings. They both illustrate the potential for improved communication between stakeholders in educational change, however the modes of interaction that are offered are different.

One strength of the Form was its use of the same evaluative framework. This allowed systematic collection of reviews, searching by criteria or context, and comparison of responses by different educators. A weakness of the Form is that it focused more on the design of the resources than their use. In contrast, the Netcourse was particularly strong at pointing to the ways tools could be used in teaching and learning. It allowed discussion to focus not so much on the resources themselves, but on their curriculum- 
based applications. Some resources have indeterminate uses (e.g., McAndrew et al., 2004), so a thorough review must address reasons, strategies, or ways of use that are envisioned. The Netcourse enabled discussion of these issues more than the Form. A weakness of the Netcourse, however, is that there was no common framework applied to the resources being reviewed and thus there was less opportunity for aggregation, searching, or recommending for use by others. In future, we envision adding a common framework to the Netcourse design when possible to allow aggregation of reviews and to build on strengths of both projects.

\section{Systematic review in professional development as systemic change}

If widely adopted, this model of systematic review as professional development holds the potential to change feedback systems among stakeholder groups in online resource development and use in education. The strategies we have outlined may be of interest to educators who perceive a benefit from interacting with and obtaining information from each other. We expect that as part of their ongoing professional development, educators will revisit sites that offer interaction with peers and chances to learn about new resources. We think our strategies for review of online resources can support the work of online communities and may come to represent one of the few available "systemic organizational frameworks that proved sustainable and scaleable across many years" (Levin \& Cervantes, p. 291). Easier opportunities to provide feedback on materials, and to see feedback from others, may stimulate participation and promote more meaningful interaction. Use of such a system could promote ongoing use by new cohorts of teachers and provide teacher educators with "a constant resource for sustaining virtual interaction" (Cole, p. xxviii).

Systematic review leading to online communities may prove to transcend problems with highly centralized approaches of the past. While centralized digital libraries have tremendous potential, they have in the past been unable to cope with the explosion of new resources arising from many quarters (Downes, 2005; Plass and Salisbury, 2002). By devolving control over criteria and evaluation to communities of use, i.e., teachers, the online community approach may be able to allow different types of review criteria to be applied and evolved as quickly as the resources themselves change in a more organic or automated fashion (Downes, 2005). Thus, the use of these types of online communities may address Lessig's (2001) concerns about whether decentralizing and democratizing efforts using the Internet can continue in the face of growing pressures for top-down control. Indeed, as Cole (2002) argues, finding ways to support communities of interest or choice has become increasingly important in modern life To a considerable extent, movement toward collaborative knowledge building among educational stakeholders requires a shift in culture and perspective. Barab and Duffy (2000) note that schooling often fails to emphasize how learners contribute to the community "all too frequently school culture accords knowledgeable skill a reified existence, commodifying it, and turning knowledge into something to be acquired" ( $p$. 34) as opposed to something that is co-constructed and shared. However, coconstruction is essential to group and organizational learning, and for the advancement of scholarship and the open source development model. Here, functional subsystems of the 
educational system such as the teacher professional development system, systems for classroom use of resources, resource evaluation, and resource development are all connected through a common community, changing the flow of information between these subsystems. See Table 2.

\section{Table 2: Systemic shifts with communities for systematic review}

\section{Old Paradigm}

Responsible for their own dissemination and research

Disseminate finished products

Rely on their own pilot sites for formative feedback

Have hard time getting feedback once products are disseminated Interest in use by primary audiences Focus on tools and functions, without focusing on context and use cases

\section{New Paradigm}

\section{Developers}

Partner with professional developers for dissemination and research

Constantly updating, revising

Partner with professional developers (in the field) to obtain feedback Continually get feedback from new cohorts of learners

Interested in re-use by diverse audiences Focus on design of tools and practices for varied contexts

\section{Researchers}

Have trouble eliciting knowledge from users

Have trouble documenting contextual variables

Focus on success or failure of interventions in situ with natural variations in adoption, adaptation

Focus on "what works"
Work with professional developers to elicit knowledge

Obtain information to understand context for use of resources and tools

Focus on means to enhance adoption, adaptation to ensure wide-ranging success

Focus on "how to make it work"

\section{Professional Developers}

Do not give feedback to developers Responsible for learning of individual teachers

Train one cohort at a time with no residual

One-shot trainings, teachers take the info and leave knowledge base
Partner with developers to offer feedback

Responsible for learning within organizations, and across the field

Build knowledge base drawing upon experience of multiple cohorts

On-going professional development, teacher take the info and come back for more

Teachers

Routinely share knowledge in a systematic (codified) way with others

Share what they find, and have ways to learn from peers on an ongoing basis Learn to apply analytic frameworks when reviewing new resources, sharing their reflections Learn and work online and virtually

\section{Information Managers}

Learn and work face-to-face

Create libraries of resources using their own or

Use their own ad hoc criteria varied lists of criteria

Do not ask for feedback about resource use recommendations 
Recommendations based on authoritative reviews
Recommendations based on non-authoritative (user) reviews

Will the systematic review be limited to influencing teacher professional development and not other subsystems? The incentive for teachers to contribute reviews during professional development is clear, but what about after their course is over? Professional development tools and web sites are often introduced with hopes that teachers will return after they matriculate from workshops or classes and are no longer required to visit the site. However, it is difficult to get people to come back to web sites. Using online communities for professional development at a distance can help reduce isolation in the classroom (Schlager, Fusco \& Schank, 2002) but it is challenging and expensive. An ongoing problem in the design of online professional development is the sustainability of these structures and incentives for busy professionals to participate, especially once they begin or return to their busy careers (Cole, 2002).

At the individual level, if useful criteria can be developed and taught, these might be adopted and used for personal knowledge management. Some educators might choose to "tag" resources using evaluative criteria that is provided (or co-constructed) and make this information available not only to themselves but also to others, as is currently the practice with "blogs using tools like Technorati to support human information mining and to "transform data into knowledge" (Orihuela, 2003). In addition to contributing metadata for their own use (and use by others), graduates may take an interest in seeing the reviews of subsequent cohorts in order to learn about the latest technologies. Thus, curiosity and self-organization are two incentives for teachers to continue reviewing outside their formal professional development.

The ideas we have presented can also be adopted as part of local school reform efforts that benefit from being linked to others. McAndrew, et al. (2004) indicate that colleagues at their college "want to know what colleagues are currently thinking, what methods and approaches are currently being used; and they want the opportunity to discuss ideas with colleagues across the university. But no one has time to attend workshops or other faceto face events to facilitate these needs" (p. 740). Professional development activities can be designed to catalyze communications in these areas. In NSN terms, the goal is for the local information infrastructure to support local needs, while both feeding into and benefiting from its connection to a larger infrastructure. The strategies we described create the conditions for sharing of resources including helping developers seek feedback from and collaborate with users, and documenting pedagogically valuable materials (Mergendoller \& Kajder, 2004),

Because the proposed approach supports and does not hinder teacher learning, it is consistent with "a dual approach working simultaneously on individual and institutional development" (Fullan, 1993, p. 12), with learning occurring at both levels, and the ability to let good ideas "rise above" others (Lamon, Reeve \& Scardamalia, 2001).

\section{Summary}


We envision networks of educational researchers and developers systematically applying and aggregating the results of systematic reviews. They may focus on resources that apply the same design principles, assessment instruments, learning goals, or teaching contexts. For instance, the TELS (Technology Enhanced Learning in Science, http://www.telscenter.org/) center is an NSF-funded Center for Teaching and Learning with an explicit mission to form an educational "accelerator" that seeks to connect researchers, teachers, and developers through multiple feedback mechanisms ranging from systematic review of resources to systematic review of research. We anticipate that the development of shared criteria by such groups will greatly enhance the potential for aggregation of results and broader impact. Technology should allow for communities to create and apply shared criteria; for instance, the Buck Institute for Education has experimented with an authorable version of the Web Site Evaluation Form with reusable, configurable criteria (See accompanying URL for related links).

All too often, the knowledge that people develop about online resources does not get shared with others who may be interested. As a result, the utility of this knowledge is diminished, claims of utility are difficult to assess, and demonstrating results is much less feasible. We hope that this will change. We urge professional developers, online community facilitators, and technology designers to consider "closing the loop" in educational systems by ensuring that knowledge gained from teacher experiences with digital resources is captured, shared, and ultimately, used by those who need it most throughout our complex educational system..

\section{Accompanying URL}

(examples and related links)

http://www.bie.org/Ravitz/bjet.html

This URL will be updated with related links, and examples from the discussed work.

\section{Acknowledgments}

The authors would like to thank the following for their critical review of this work as well as their helpful encouragement, rephrasing and suggestions: Judi Harris, Nathan Bos, Charalambos Vrasidas, Don Ely, Jerry Kemp, Bryan Alexander, Charles Reigeluth and the anonymous reviewers. 
Ravitz \& Hoadley, To appear in British Journal of Educational Technology March, 2005

\section{REFERENCES}

Allert, H. Richter, C. \& Nejdl, W. (2004). Lifelong learning and second-order learning objects. British Journal of Educational Technology, 35(6), 701-715.

Bannan-Ritland, B., Dabbagh, N. \& Murphy, K. (2000). Learning object systems as constructivist learning environments: Related assumptions, theories, and applications. In D. A. Wiley (Ed.), The instructional use of learning objects. [WWW Document]. URL http://reusability.org/read/chapters/bannan-ritland.doc

Barab, S. \& Duffy, T. (2000). From practice fields to communities of practice. In D. Jonassen \& S. Land (Eds.). Theoretical foundations of learning environments. Mahway, NJ: Lawrence Earlbuam Associates, 25-56.

Barbera, E. (2004). Quality in virtual education environments. British Journal of Educational Technology, 35(1), 13-20.

Becker, H. J. (1995). National School Network Testbed Phase 2 Baseline of TestbedParticipating Schools. [WWW Document]. URL http://www.bie.org/Ravitz/Becker/NSN_Baseline.pdf

Black, P., \& Wiliam, D. (1998). Inside the black box: Raising standards through classroom assessment. Phi Delta Kappan, October. [WWW Document]. URL http://www.pdkintl.org/kappan/kbla9810.htm

CEO Forum (2001, June). School technology and readiness report. [WWW Document]. URL http://www.ceoforum.org/downloads/report4.pdf

Chitwood, K., May, C., Bunnow, D., \& Langan, T. (2000). Battle stories from the field: Wisconsin online resource center learning objects project. In D. A. Wiley (Ed.), The instructional use of learning objects. [WWW Document]. URL http://reusability.org/read/chapters/chitwood.doc

Cole, M. (2002). Virtual communities for learning and development - A look to the past and some glimpses into the future. In K. Renninger and W. Shumar (Eds.), Building virtual communities: Learning and change in cyberspace. New York, NY: Cambridge University Press, xxi-xxix.

Collings, P. \& Pearce, J. (2002). Sharing designer and user perspectives of web site evaluation: a cross-campus collaborative learning experience. British Journal of Educational Technology, 33(3), 267-278.

Collison, G., Elbaum, B., Haavind S., \& Tinker, B. (2000). Facilitating online learning: Effective strategies for moderators. Madison, WI: Atwood.

Curtis, P. Lecture, Northeastern University, Boston, MA. 3/13/95.

Downes, S. (2005). Emergent Learning: Social Networks and Learning Networks.

[WWW Document]. URL http://www.downes.ca/files/osn.html

Ely, D. \& Huberman, A. (1994). User-friendly handbook for project dissemination. NSF Publication \#94-17. Washington, DC: National Science Foundation, Division of Research, Evaluation and Dissemination.

Frechtling, J.A. (Ed.). (1995). Footprints: Strategies for Non-Traditional Program Evaluation (NSF 95-41). Arlington, VA: National Science Foundation, Division of Research Evaluation and Dissemination.

Fullan, M. (1993). Change Forces. London: The Falmer Press.

Gilbert, N \& Driscoll, M. (2002). Collaborative Knowledge Building: A Case Study. Educational Technology, Research \& Development, 50(1). p. 59-79. [WWW Document]. URLhttp://www.aect.org/pdf/etr\&d/5001/5001-05.pdf 
Ravitz \& Hoadley, To appear in British Journal of Educational Technology March, 2005

Glenn, A. \& Whitaker, S. (2004) Open Resources and Public/Private Partnerships. In Bull \& Garofalo, Eds. (2004).

Haertel, G., \& Means, B. (2000). Stronger designs for research on educational uses of technology: Conclusion and implications. Menlo Park, CA: SRI International. [WWW Document]. URL http://www.sri.com/policy/designkt/found.html

Harris, J. \& Swan, K. (2004). An educational open source development model: From cooperative synchronicity to intentional collaboration. In Bull \& Garofalo, Eds. (2004).

Hoadley, C. M. \& Pea, R. D. (2002) Finding the ties that bind: Tools in support of a knowledge-building community. In K.A. Renninger and W. Shumar (Eds.), Building virtual communities: Learning and change in cyberspace. New York, NY: Cambridge University Press, 321-354.

Hunter, B. (2002). Learning in the virtual community depends on changes in local communities. In K.A. Renninger and W. Shumar (Eds.), Building virtual communities: Learning and change in cyberspace. New York, NY: Cambridge University Press, 96-128.

Hunter, B. (1995, November). Internetworking and educational reform: The National School Network Testbed. Paper to be presented at the International Networking Conference, '95. [WWW Document]. URL http://copernicus.bbn.com:70/testbed2/TBdocs/065.hunter.html.

Hutchings, P. \& Shulman, L. (1999). The scholarship of teaching: New elaborations, new developments. Change, September/October 1999. Volume 31, Number 5. Pages 10-15. [WWW Document]. URL http://www.carnegiefoundation.org/ elibrary/docs/sotl1999.htm

Lamon, M., Reeve, R., \& Scardamalia, M. (2001, April). Mapping learning and the growth of knowledge in a knowledge building community. In Scaradamalia (Chair), New directions in knowledge building. Annual meetings of the American Educational Research Association. Seattle, WA.

Lessig, L. (2001). The future of ideas: The fate of the commons in a connected world. New York: Random House.

Malcom, M. (2005). The exercise of the object: issues in resource reusability and reuse. British Journal of Educational Technology, 36(1), 33-41.

McAndrew, P., Clow, D. Taylor, J. \& Aczel, J. (2004). The evolutionary design of a Knowledge Network to support knowledge management and sharing for lifelong learning. British Journal of Educational Technology, 35(6), 739-746.

Mergendoller, J. \& Kajder, S. (2004). Open Resources and Teacher Education. In Bull \& Garofalo, Eds. (2004).

MERLOT. (2005). Evaluation standards for learning materials in MERLOT. [WWW Document]. URL http://taste.merlot.org/catalog/peer_review/eval_criteria.htm.

Moallem, M. (2003). An interactive online course: A collaborative design model. Educational Technology Research \& Development, 51(4), 85-103.

National Educational Technology Standards for Teachers (2004a). [WWW Document]. URL: http://cnets.iste.org/teachers/t_book.html

National Educational Technology Standards for Teachers (2004b), Appendix D: Sample Software and Web Site Evaluation Forms [WWW Document]. URL http://cnets.iste.org/teachers/pdf/Appendix_D.pdf 
Ravitz \& Hoadley, To appear in British Journal of Educational Technology March, 2005

Orihuela, J. (2003). Blogging and the eCommunication Paradigms: 10 principles of the new media scenario. BlogTalk, A Eurpoean Weblog Conference. Vienna, Austria. May 23-24. [WWW Document]. URL http://mccd.udc.es/orihuela/blogtalk

Orrill, C. H. (2000). Learning objects to support inquiry-based online learning In D. Wiley (Ed.), The instructional use of learning objects. [WWW Document]. URL http://reusability.org/read/chapters/orrill.doc

Pea, R.D., Tinker, R., Linn, M., Means, B., Bransford, J., Roschelle, J., Hsi, S., Brophy, S., \& Songer, N. (1999). Toward a learning technologies knowledge network. Educational Technology Research and Development, 47(2).

Peck, K. L., Augustine, C., \& Popp, J. D. (2003). The AECT Project: Modeling the effective use of technology in teacher preparation. Tech Trends, 47(2), 21-23.

Plass, J. and Salisbury, M. (2002) A living systems design model for Web-based knowledge management systems. Educational Technology, Research \& Development, 50(1), 35-57.

Ravitz, J. (2004). A doorway to new tools and practices: Supporting teacher education, research, and development with an online netcourse. In N. Sabelli and R. Pea (Eds.). Center for Innovative Learning Technologies: Six years of knowledge networking in learning sciences and technologies. Menlo Park, CA: SRI International. (pp. 88 -95). [WWW Document]. URL http://www.bie.org/research/tech/summary2.php?id=41

Ravitz, J. \& Serim, F. (1997, April). Summary of first year evaluation report for the Online Internet Institute. Edward F. Kelly Evaluation Conference. SUNY, Albany. Albany, NY. [WWW Document]. URL http://www.bie.org/Ravitz/oii_summary.html

Ravitz, J. \& Lake, D. (1996, June). An authentic learning tool for teachers: the OII $W W W$ site evaluation form. FSU/AECT Conference on Distance Learning. Tallahassee, FL. [WWW Document]. URL http:/www.bie.org/Ravitz/authentic.html

Ravitz, J. (1995). Building collaborative online communities for $K-12$. Proceedings of the Mid-continent Institute's fourth annual Innovations in Education Conference, Minot State University, Minot, ND., November 9-12, pp. 71-83. [WWW Document]. URL http://www.bie.org/Ravitz/Ravitz_Paper_8_95.html

Recker, M., Walker, A., \& Wiley, D. (2000). Collaboratively filtering learning objects. In D. A. Wiley (Ed.), The instructional use of learning objects. [WWW Document]. URL http://reusability.org/read/chapters/recker.doc

Recker, M. and Wiley, D. (2001) A non-authoritative educational metadata ontology for filtering and recommending learning objects, Journal of Interactive Learning Environments, Swets and Zeitlinger, The Netherlands

Renninger and W. Shumar (Eds.), Building virtual communities: Learning and change in cyberspace. New York, NY: Cambridge University Press.

Riding, P., Fowell, S., \& Levy, P. (1995). An action research approach to curriculum development. Information Research, 1(1) [WWW Document]. URL http://InformationR.net/ir/1-1/paper2.html

Rogers, E. (1983). Diffusion of innovations ( $3^{\text {rd }}$ edition). New York City: Free Press.

Sabelli, N. \& Pea, R. (Eds.). (2004). Center for Innovative Learning Technologies: Six years of knowledge networking in learning sciences and technologies. Menlo Park, 
Ravitz \& Hoadley, To appear in British Journal of Educational Technology March, 2005

CA: SRI International. [WWW Document]. URL http://ctl.sri.com/publications/downloads/CILT_final.pdf

Schlager, M., Fusco, J. \& Schank, P. (2002). Evolution of an online education community of practice. In K. Renninger and W. Shumar (Eds.), Building virtual communities: Learning and change in cyberspace. New York, NY: Cambridge University Press, 129-158.

Shepherd, C. (2000). Objects of interest. Brighton East Sussex: Fastrak Consulting Limited. [WWW Document]. URL http://www.fastrakconsulting.co.uk/tactix/features/objects/objects/htm.

Tripp, S. D., \& Bichelmeyer, B. (1990). Rapid protoyping: An alternative instructional design strategy. Educational Technology, Research and Development, 38(1), 31-44.

Walton, M. \& Archer, A. (2004). The Web and information literacy: scaffolding the use of web sources in a project-based curriculum. British Journal of Educational Technology, 35(2), 173-186.

Weinberger, D. (2004). Digital future: Blogging. C-SPAN Forum. Filmed at the Library of Congress Washington, District of Columbia (United States). 11/15/2004.

[WWW Document]. URL http://inside.cspanarchives.org:8080/cspan/cspan.csp? command=dprogram\&record $=59296818$

West, C., Farmer, J., \& Wolff, P. (1991). Instructional design implications from cognitive science. Englewood Cliffs, NJ: Prentice Hall.

Wiley, D. A. (2000). Connecting learning objects to instructional design theory: A definition, a metaphor, and a taxonomy. In D. A. Wiley (Ed.), The Instructional Use of Learning Objects: Online Version. Retrieved May 5, 2003, from the World Wide Web: http://reusability.org/read/chapters/wiley.doc 